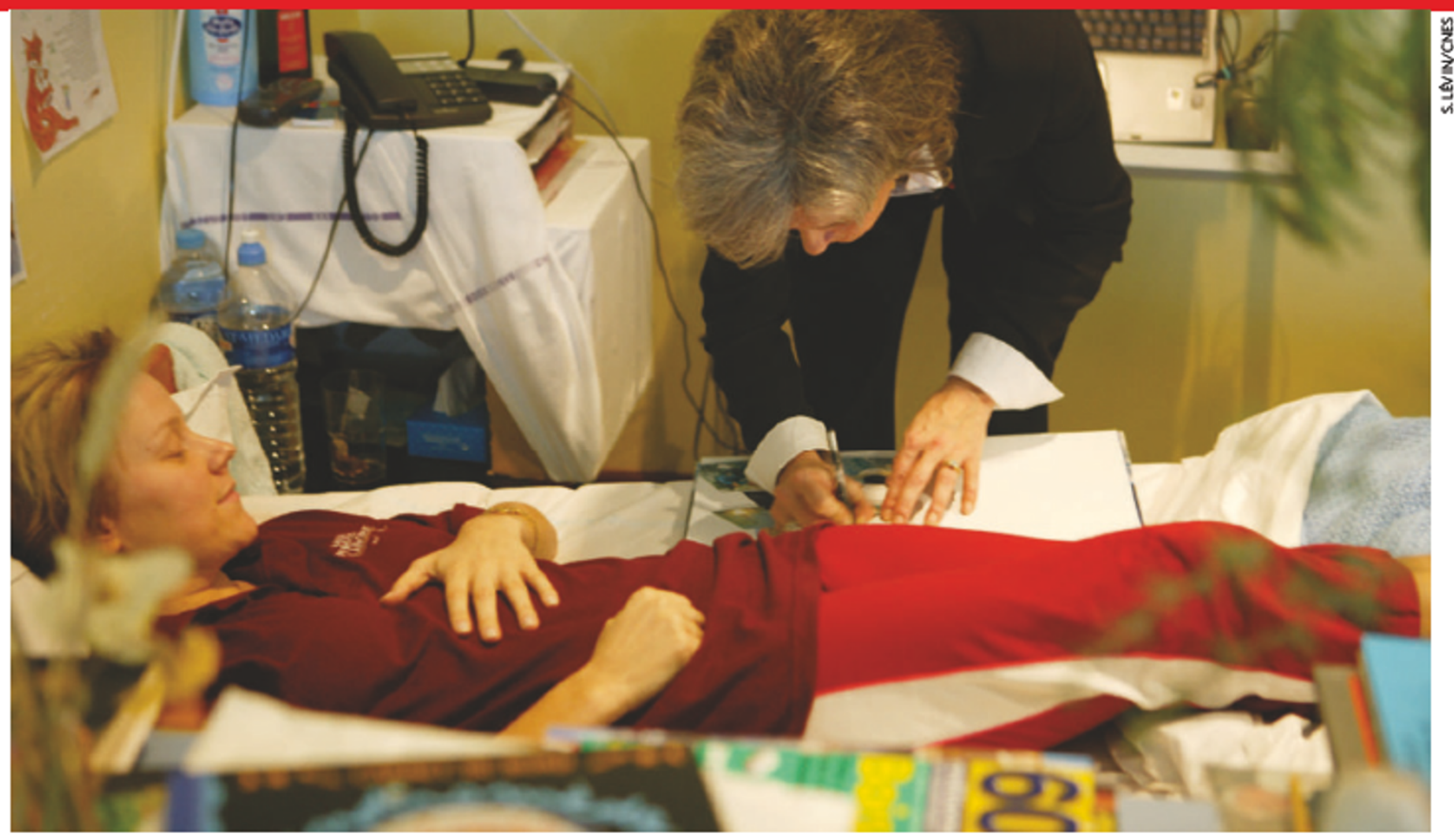

\title{
Lie back and think of science
}

\section{Twelve women have taken to bed for two months in the name of space research. Nicola Jones joins them for a few days, and asks what physiologists hope to learn from this marathon lie-in.}

'm staring at the ceiling and my feet are strapped to an exercise machine that acts like a giant yo-yo. My head rests a few centimetres lower than my feet, my face is bright red and my calves are screaming in pain as Björn Alkner, trained in physiology and physical education, yells at me to push the last set of repetitions to the maximum.

The exercise session ends and, unstrapped, I give in to the overwhelming desire to stand up and stretch. Instantly, I feel dizzy and my head pounds. Perhaps I'm not cut out for this. I've been here for just half an hour, but in the other rooms of this squat building at Toulouse's Rangueil Hospital lie women who have signed up to submit themselves to such procedures for two months - during which time they won't be able to sit or stand at all.

These volunteers will be pumped full of glucose, fed protein drinks, jabbed for blood samples and muscle biopsies, given electrical stimulation to make their muscles twitch, asked to run on a vertical treadmill, and much more. With no apparent irony, the researchers running this international project describe the experience as 'bedrest.'

They may seem like sadists, but the leaders of the project - run by MEDES, the French Institute for Space Medicine and Physiology in Toulouse - have a serious purpose. If astronauts are to spend longer stints in orbit, or make the 30-month return trip to Mars, we need more data on how the body responds to microgravity - and how to mitigate its damaging effects on our physiology. Bedrest studies have for decades been used to mimic the weightlessness of space, but there is still much to learn; particularly about women, who have been under-represented in these experiments.

\section{Difficult position}

So the dozen volunteers in Toulouse are pioneers. "They are doing it for the sense of adventure," says MEDES project scientist Marie-Pierre Bareille. They certainly aren't in it for the money. Each volunteer will get $€ 15,000$ (US\$18,000) in instalments over four years. But it's a strange kind of adventure: the dosest these women will get to the International Space Station (ISS) this summer is looking at its photo on the wall of the exercise room. For 60 days, they will lie with their heads at a $6^{\circ}$ downwards slant, while they eat, shower...do everything, in fact. There are even discreet cameras in place to ensure that they don't cheat.

Despite this, the volunteers are enthusiastic. ${ }^{\alpha}$ The last time I thought about being an astronaut was when I was five years old," says the recumbent Dorota Tataruch, a 25-year-old student from Poland. "But all this is fascinating - talking to the scientists; seeing how we respond psychologically. I'm glad I'm here."
Lying down with your head lower than your feet may seem a poor imitation of the conditions in space, but it has many of the same physiological effects. After a few hours, blood and other fluids shift towards the head, making for a puffy face and headaches. After a day or so, the body responds to the increased volume of fluid in the upper torso: astronauts and bedrest volunteers quickly lose up to a litre of urine. Meanwhile, the lack of stimulation to balance sensors in the ears and nerves in the soles of the feet can cause dizziness and nausea. Astronauts can experience debilitating space sickness, and bedrest volunteers sometimes get a milder vertigo - usually relieved, for unknown reasons, by gently shaking the sufferer's head.

Leg and back muscles begin to atrophy calf muscles can shrink by up to $30 \%$ within a few months, with a $50 \%$ reduction in some measures of leg strength. Every month, up to $2 \%$ of bone in the same areas is lost. As calcium leaches out, there's an increased risk of kidney stones. Without exercise, the body's control of blood glucose goes awry, potentially leading to insulin resistance. And without the effort of having to pump blood against gravity, the heart muscles shrink and 'forget' this crucial aspect of their function.

Even with two hours of exercise a day and a good diet, astronauts return to Earth severely weakened after a few months in space. "We 
5 have some crew members who can't get out of their seats or walk," says Jeffrey Jones, head of NASA's medical operations for exploration missions at the Johnson Space Center in Houston, Texas.

Most bedrest studies to date have focused on changes in blood flow, bone and muscle mass. This study will also look at these effects, but with a few novel twists - including the gender make-up of the study group. Although there is no reason to think that female physiological responses to rest are radically different from men's, there are bound to be hormonal differences. And there are hints that women might faint more easily after a period in low gravity than men.

\section{Undercover agents}

The 12 women in the study have been split into three groups - one to explore the effects of exercise, one to test a high-protein diet, and the other serving as a control. But all face mental challenges. "Boredom and privacy are the first issues. Then you expect some to become short-tempered," says François-Régis Lenoir, a psychological counsellor on the trial. After 1,600 enquiries and 240 serious applications, only the most mentally and physically fit were selected. Still, there are bound to be difficulties. Tataruch's roommate had her 30th birthday while lying down, and all the team could do to celebrate was to wheel her outside for a bit of sunshine. At times, Tataruch and her nutrition-testing colleagues have been desperate to go for a run.

At least the exercise group has some sort of release. These women are testing two devices: the first is the yo-yo contraption I struggled with. This works like the squat-machines found in most gyms, although instead of lifting weights, you pull against the resistance of a nylon strap wrapped around a spindle. This exercises the thighs and calves, especially prone to muscle loss in space. The device performed well in a bedrest study with men, reportedly being both more effective and comfortable than the machines currently on the ISS - which include a stationary bike and a

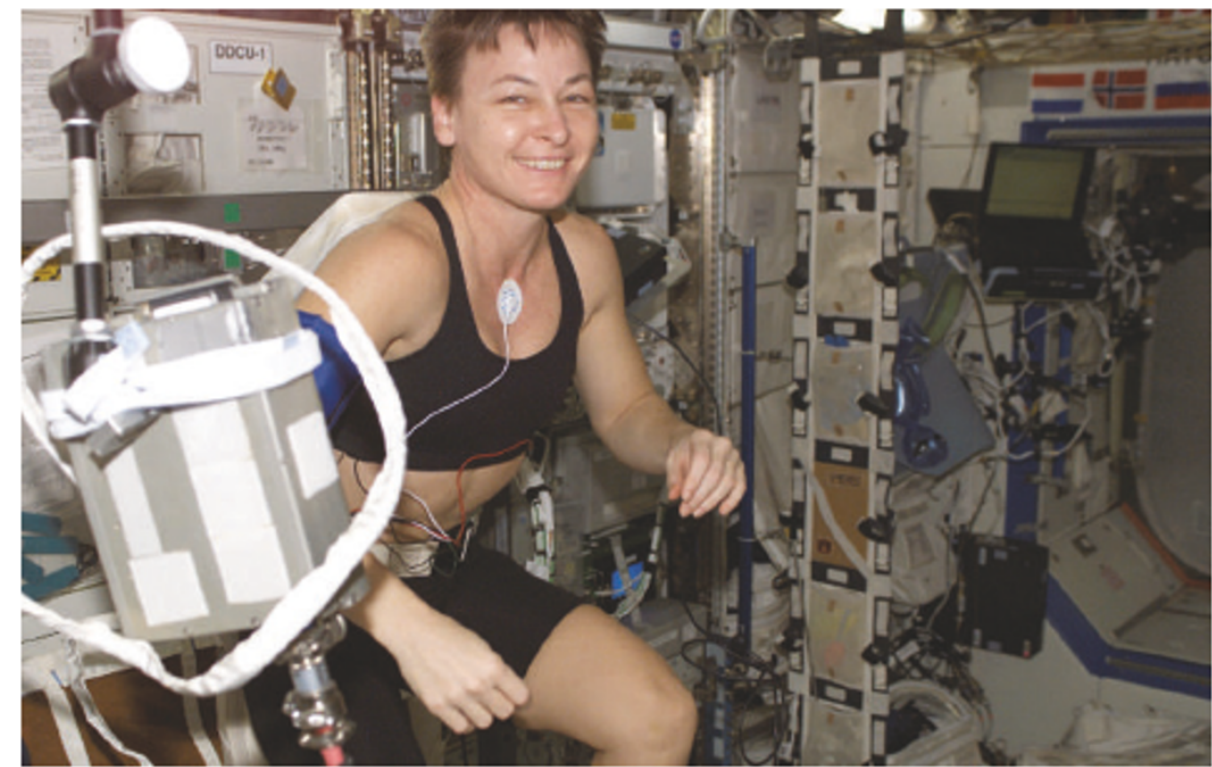

Training station: astronauts mus texercise in space to stop their leg muscles from wasting away.

treadmill that astronauts attach themselves to with bungee cords. ${ }^{\alpha}$ They're designing a model to test on the ISS now," says Alkner.

The second device is a vertical treadmill encased in a plastic box. The women are inserted into it sideways and air is extracted, which sucks the feet onto the jogging surface. This also pulls the blood to the feet, forcing the heart to work harder. It's an odd sensation being trussed up and swung into the device. Then the pump comes on and my feet hit the treadmill with a thud. It feels strange, but it works: now I'm running up the wall. Through about an hour of such exercises each day, researchers hope that the active group will retain $100 \%$ of their leg muscles - a feat never yet achieved.

The second experimental group is testing the idea that muscle loss can be minimized simply by eating a high-protein diet laced with extra leucine - an amino acid thought to be crucial to muscle building. "This should halve the amount of muscle loss," says Gianni Biolo from the University of Trieste in Italy, who is principal investigator on the project. The leucine comes in powdered

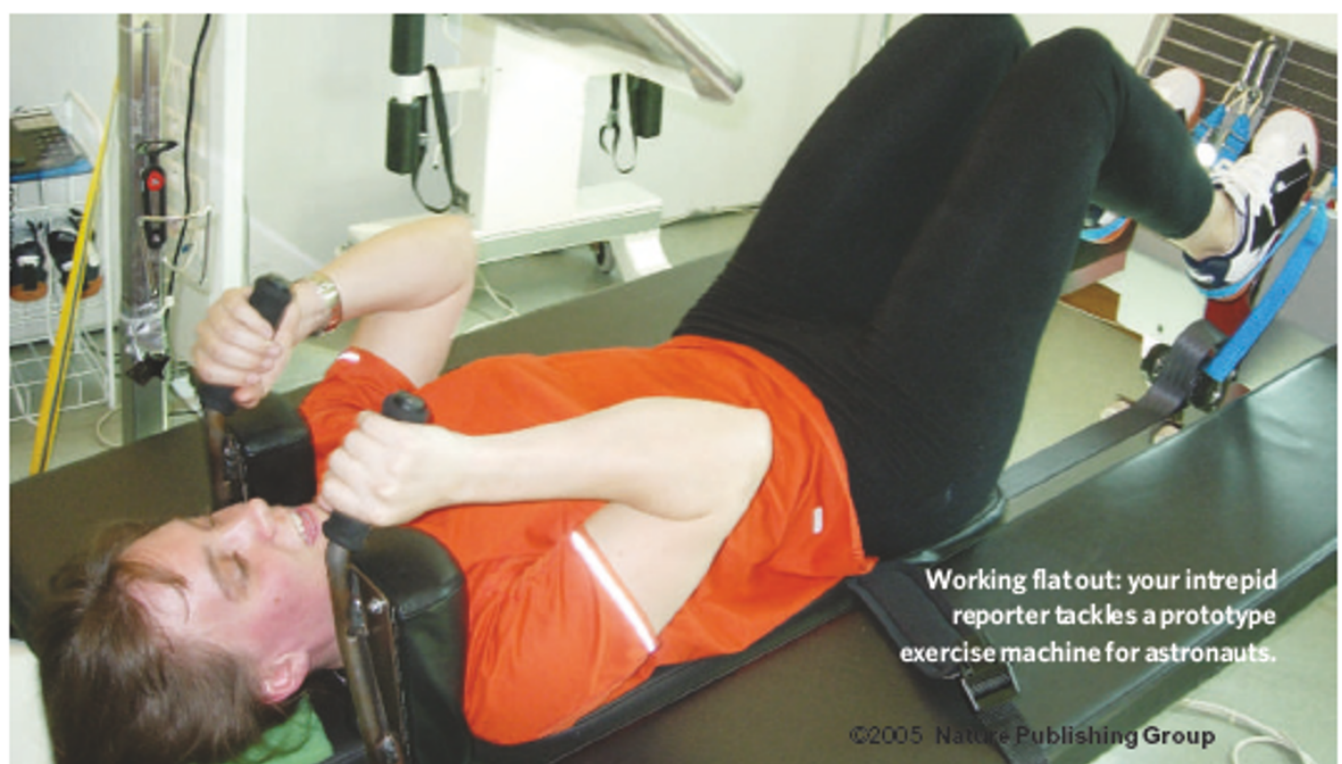

form. Added to water, it tastes foul.

Maintaining muscle mass and tone is one thing, but the effects of microgravity or bedrest on our nervous system and balance are harder to tackle. "That's our greatest weakness. It would be great if people focused more on that," says Jones. The Toulouse researchers will be looking at how some of our nerves and leg muscles work together through reflexes to help us walk without stumbling or falling over using electrical stimulation, they will monitor how these reactions change with rest.

\section{Bedside manner}

Other project scientists are examining the effects of simulated microgravity on everything from the immune system to mental acuity. But the volunteers seem strangely subdued in the face of all this poking and prodding. They read, write e-mails or chat to each other. Counsellors and massage therapists are on hand to attend to any psychological and physical niggles.

When I call Tataruch from London to find out how her two months of 'rest' went, she is in good humour. "It passed much quicker than I expected," she says. Full results from the experiments won't be available for a while, but the diet and exercise regimes seem, from Tataruch's account, to have had the desired effect. Members of the control group managed to stand, albeit with a few wobbles, and painful backs and feet. Tataruch's leg muscles are visibly larger than theirs, she says, although smaller than those in the exercise group.

Now Taturach faces a month of rehabilitation, to get back into sports and - she can't wait for this - real food. She says that the experience has prompted her to think about applying for astronaut training when she becomes eligible in a few years' time.

In the meantime, the same scientists are looking for more participants for bedrest. Any volunteers?

Nicola Jones is editor of news@nature.com. 